\title{
Education for All: The Case of Out-of- School Migrants in Ghana
}

\author{
Daniel Owusu Kyereko
}

\section{INTRODUCTION}

The world has witnessed significant progress toward increasing access to education for children of school-going age since the 1990 World Conference on Education in Jomtein. But for many in countries in subSaharan Africa, the goal of achieving universal access to education remains elusive. Children in sub-Saharan Africa comprise a major portion of the out-of-school population, with children of migrants identified as being among the most vulnerable and most at risk of dropping out of school (Majgaard \& Mingat, 2013; United Nations Educational, Scientific and Cultural Organization [UNESCO], 2010; UNESCO Institute for Statistics [UIS], 2017; UIS and Global Education Monitoring Report [GEMR], 2016).

In 2017, South-South migration accounted for 38\% of 258 million international migrants documented worldwide. Over a third of all international migrants moving from the South settled in another country in the global South (United Nations Conference on Trade and Development

D. O. Kyereko $(\bowtie)$

Bayreuth International Graduate School of African Studies, Bayreuth, Germany e-mail: Daniel.Kyereko@uni-bayreuth.de

(C) The Author(s) 2020

M. L. McLean (ed.), West African Youth Challenges and

Opportunity Pathways, Gender and Cultural Studies in Africa and the Diaspora, https://doi.org/10.1007/978-3-030-21092-2_2 
[UNCTAD], 2017). Motivations for contemporary South-South migration can be partly attributed to the increasingly restrictive immigration policies being introduced in countries of the Global North and the growth in the economies of countries within the Global South. Migration between neighboring countries accounts for about $84 \%$ of all migration in West Africa (Awumbila, 2017; Bartlett, 2015; Ratha \& Shaw, 2007). According to the 2010 Population and Housing Census in Ghana, migrants account for about $2.5 \%$ of the country's population. Migrants from within West Africa account for $68.3 \%$ of Ghana's migrant population (Ghana Statistical Service, 2013). This immense increase in South-South migration not only impacts schooling in host countries but also global efforts to achieve the Sustainable Development Goals (SDGS). Thus, studying out-of-school migrants and the motivations underpinning their choice to stay out of school has broad national and global policy implications.

This study delves into the experiences of migrants in Ghana with the aim of uncovering the factors that prevent them from enrolling in schools. The major question the research seeks to answer is: What are the obstacles keeping migrant children and youth out of school in Ghana? In answering the question, the work tries to distinguish which obstacles are migration related and which ones are not migration related. It also seeks to ascertain whether some groups of migrant children are more prone to being out of school than others. The analysis is based primarily on interviews with migrant children, migrant parents, and school authorities (head teachers and teachers).

\section{LITERATURE REVIEW}

Research shows that migrant children and youth across the world face challenges in exercising their rights to education due to their lack of adequate documentation. The requirement that migrants provide documents to prove their age, immunization history, and residency before being admitted into schools often serves as a barrier that limits their access into educational systems (Buckland, 2011; Crush \& Tawodzera, 2011; Greenberg, Adams, \& Michie, 2016; Heckmann, 2008; Nusche, 2009). In a study of a third of migrants sampled from countries in the Global North, the United Nations Development Programme (UNDP) (2009) found migrants without proper documentation stayed out of school. The research showed that in countries such as Belgium, where education is free and compulsory for citizens, education is not compulsory for children of 
migrants without the required legal documentation. Further, in Poland the lack of documentation also impacted public funding for education, as children of migrants without proper documentation are not counted by the schools and thus are not included in school population statistics reported to the state. The lack of funding coverage by the state limited the migrants' access to schools. Even in countries that guarantee the right to education for all regardless of legal status, fear of being reported to authorities made migrants without the required authorization reluctant to place their children into the educational system. In countries where education is not entirely free, the inability to pay school fees and other associated costs also served as a barrier that prevented migrants from attending schools (UNDP, 2009).

Schapiro (2009) maintained that children migrating alone are the most disadvantaged when it comes to education. She asserted that such children face barriers to school enrollment that are difficult to overcome. Migrants without the requisite documentation, as well as documented migrants, face challenges to accessing school systems. Crush and Tawodzera (2011) and Buckland (2011) shed more light on the barriers migrant children face, regardless of legal status, when accessing education in host countries. Their research centering on migrants and schooling in South Africa demonstrated how the absence of proper documentation often forced migrant children to stay out of school. The status of migrants had a telling effect on the way they even accessed support within the school system, with undocumented migrants often missing out. These barriers often encourage migrants to stay out of school. In addition to barriers stemming from their migrant status (whether they are unaccompanied by adults, documented, or undocumented) child migrants also face traditional access barriers that impede school access for native-born children in the host country as well, such as the lack of funds to cover fees and other school-related costs (uniforms, books, transportation, feeding). Crush and Tawodzera (2011) and Buckland (2011) point out that, regardless of legal status, migrants face additional challenges in accessing education in their host country. Xenophobic attacks, barriers associated with language, and lack of access to information are some challenges keeping migrants out of school. Additional problems faced by out-of-school migrants can be attributed to policies that are not explicit on how migrants' education should be managed within host states (Buckland, 2011; Crush \& Tawodzera, 2011). 
Schapiro (2009) further posited, based on evidence from case studies, that many of these challenges are encountered when migrants move to the level of education that is not compulsory and free. She cites the case of migrants without required legal documentation in the United States, who have difficulty accessing college funding from public universities.

For Sabates-Wheeler (2009), the line between migrants without the right documentation and migrants with the required documentation is blurred. For example, issues of language, which many countries fail to address, affect migrants whether they have the necessary documentation or not (Sabates-Wheeler, 2009). Citing research in South Africa, SabatesWheeler (2009) posited that even legal migrants are sometimes denied school access as school authorities deem their documents insufficient to meet admission requirements. Although in such cases migrants have a right to seek legal action, their lack of awareness and the inaccessibility of the legal system prevents them from doing so (Sabates-Wheeler, 2009).

Research suggests school access for migrants also depends upon the economic standing of the country of destination. Migrants who move to the richer countries in the Global North are more likely to have better entry into schools than those migrating to countries in the Global South. Furthermore, migrants from the Global South who migrate to the Global North on temporary visas have problems gaining access to schools. Other factors that account for the high rate of out-of-school migrants include the nature of work their parents or other adult caregivers are engaged in, usually poor and hazardous working conditions, as well as the segregation within the sociocultural environment (Green, 2003; Schapiro, 2009; Stevenson \& Beck, 2017). According to Stevenson and Beck (2017), educational disadvantage among children of migrant farm workers in the United States remains pronounced. They cite dropout rates among children of the migrant farmworkers as the highest among any group in the country. In their research focused on a summer literacy program for intermediate and middle-level children of migrant farmworkers, Stevenson and Beck (2017) noted that, despite the dangerous nature of the agriculture jobs that migrant parents and children are involved in, these jobs are poor paying. The need to make ends meet forced migrant children to join parents on the farm fields as a financial necessity to augment family resources, distracting their time and attention from schoolwork.

According to Christianakis (2010), despite concerted efforts aimed at getting Roma migrants into schools in many European countries, the problem persists. Many Roma parents decide against sending their children 
to schools because they deem the school curricula to be unimportant and irrelevant to problems in their everyday life. In her work on Roma children in Greece, Christianakis (2010) points out the role of cultural assimilation in serving as a barrier that keeps many Roma migrants from enrolling in school. By distancing themselves from people outside the Roma ethnic group, they avoid all institutions that might create avenues for integration, including schools.

The circular, temporary, and repetitive nature of migration for some migrant workers serves as another distinctive barrier to the education of their children. This is most visible in the case of children who are passive movers accompanying seasonal working parents on their migration journeys. The lack of economic opportunities may push parents to migrate into areas where they can be engaged in meaningful economic activity. This may affect their desire to enroll their children in schools. Rigid school admission policies may also serve as disincentives for these children, as frequent relocation with parents may not be in alignment with formal school rules. Migrants without the requisite documentation in South Africa, according to Sabates-Wheeler (2009), were denied access because they were unable to produce the required residency permits and had no right to appeal such treatment. This may in some cases prevent them from enrolling in the first place or, for those who are already enrolled, force them to drop out (Burra, 1995).

The limited literature on South-South migration compared to NorthSouth migration points to the need for more research on migration and education among Global South nations. This research gap is especially acute with respect to intra-African migration, as most of the work on migration and education focuses on South Africa. Additionally, the existing literature employs a limited definition of access to education. For instance, most of the research focuses on migrants who drop out of school. There is little research that examines the factors preventing them from enrolling in the first place.

\section{Definition of Terms}

The definition of out-of-school children differs across research. The various definitions broadly include children who are not enrolled in school, children who are in school but are not learning, and children who have dropped out of school. This study defines out-of-school migrants as children and youth between the ages of 6 and 21 who are either not enrolled 
in, or have dropped out before completing, basic education. Although education is compulsory in Ghana from ages 4 to 14 , this study focused on migrant children from age 6 to 21 , as it considered children of age 6 and above old enough to articulate their views and thus be active voices in the research. The extension above 14 years allowed for the experiences of older children outside of the official age group to be captured. Adjusting the definition allows for the many migrants who fall out of the age limitation of UNESCO to be included. This research focuses on basic education in Ghana, which encompasses kindergarten, primary school, and junior high school.

\section{Methodology}

The study that is the subject of this chapter adopted a qualitative research approach aimed at collecting rich data. The researcher employed an interpretive approach to arrive at the research conclusions. Interpretivism involves arriving at an understanding of the social space by analyzing the worldview of the target group. It assumes that the interpretation social actors give to events is important in constructing their reality (Guba \& Lincoln, 1994). Accordingly, this research constructed knowledge by focusing on the perceptions of migrant children, migrant parents, and school authorities, as well as the underlying motivation for migrant children and youth to stay out of school.

A purposive sampling technique was complemented by snowballing with the target population usually belonging to networks relevant to the work. This was important in helping facilitate access to the target group. The study utilized semi-structured interviews. This afforded the participants the flexibility to express their views while being guided by the overarching aim of the research. Interviews were conducted with migrant children and parents. Migrant children and parents interviewed did not constitute households; the migrant children and parents interviewed were not from matching families. In total, the researcher interviewed 40 migrant children and youth (30 males and 10 females) and 20 parents (12 males and 8 females). The researcher also interviewed 40 school heads and teachers (20 males and 20 females). The number of interviews was determined when each sample population reached its point of saturation.

To ensure anonymity and confidentiality, all names used in this chapter to represent participants are pseudonyms. Migrants interviewed, whether children or parents, were either unemployed or employed within low-level 
paying jobs. All participants interviewed had migrated to Ghana for at least three months. All interviews were conducted by the author as the primary researcher. Interviews took place during three field trips to Accra, Ghana: from May to July 2015, September to November 2016, and July to October 2017. All migrants interviewed lived within Accra, the capital of Ghana. Accra is in a region that hosts the largest number of nonGhanaian population (58.4\%) (Ghana Statistical Service, 2013).

Thematic analysis was adopted in the analysis of the data through the identification of common themes that emerged during the interviews. All interviews were transcribed; codes were generated from these transcripts and subsequently drawn into thematic categories. Thematic analysis provided the research with the flexibility that was needed by drawing patterns from interviews regardless of how complex or simple they were. Adopting thematic analysis served as a foundation for this qualitative work. The thematic analysis of the data was guided by Braun and Clarke's (2006) guide regarding the utilization of the approach; thus, themes that did not occur often and those that were not salient to the work were discarded (Tables 2.1 and 2.2).

\section{FINDINGS}

\section{Lack of Awareness of Fee-Free Education at the Basic Level}

Existing research shows that parental decisions not to enroll migrant children into schools often stem from lack of information about the workings of educational systems in host countries. The limited information available

Table 2.1 Country of origin of out-of-school migrants

\begin{tabular}{lcc}
\hline Country & Frequency & Percent (\%) \\
\hline Benin & 1 & 2.5 \\
Burkina Faso & 2 & 5.0 \\
Ivory Coast & 3 & 7.5 \\
Mali & 4 & 10.0 \\
Niger & 21 & 52.5 \\
Nigeria & 7 & 17.5 \\
Togo & 2 & 5.0 \\
Total & 40 & 100.0 \\
\hline
\end{tabular}

Compiled from the fieldwork 
Table 2.2 Country of origin of parents with out-of-school children

\begin{tabular}{lcc}
\hline Country & Frequency & Percent (\%) \\
\hline Guinea & 1 & 5.0 \\
Mali & 3 & 15.0 \\
Niger & 12 & 60.0 \\
Nigeria & 3 & 15.0 \\
Togo & 1 & 5.0 \\
Total & 20 & 100.0 \\
\hline
\end{tabular}

Compiled from the fieldwork

to migrant parents undermines their ability to maximize educational opportunities that exist outside their countries of origin (Platform for International Cooperation on Undocumented Migrants [PICUM], 2012; Organization for Economic Co-operation Development [OECD], 2016; United Nations International Children's Emergency Fund [UNICEF], 2017). Nusche (2009) thus emphasized the importance of providing migrant parents with information on the educational system that will aid them in making good choices.

This research on Ghana confirms that ignorance on the part of migrant parents and children is a factor contributing to their failure to enroll in schools. Most migrant parents whose children were not in school knew nothing about the educational system and the support available at the basic level of education in Ghana, which is made up of two years of kindergarten, six years of primary education, and three years of junior high school. For instance, these migrants were not aware of the fee-free public school education offered at the basic level in Ghana. They also did not understand the repercussions of not sending their children to school in Ghana, where schooling is compulsory for all children. The shorter the duration of stay in the country, the more likely the migrant was to cite lack of information on the educational system as a cause for not sending their children to school.

Sadat, a migrant parent from Mali stated:

We have been in this country for close to a year. I have a wife and two children. I don't think about education in this country. I am not aware of any of the laws that govern education in Ghana. I am not aware that education is free at the basic level. This is new to me. I will try and verify what you said 
and take my children to school provided it is true that education at the basic level is free.

Another participant, Dassa, said, "No one has told us anything about education since we came to Ghana. We came here to make a living. We are unaware education is free at the basic level."

Although the lack of information was the most common reason migrant parents and migrant children gave for not enrolling in school, probing further showed deeper and unexplored stories behind their present circumstances. This was confirmed by the many migrants who had never tried enrolling in schools. One Nigerian parent, Abu, said, "I have not even made the attempt of sending him to school. I have never been approached by any official about going to school."

\section{Temporary Migration as a Barrier to Education Access}

Another common reason cited by migrant parents whose children were out of school was their intention not to stay permanently in Ghana. Although in some cases such migrants had stayed for more than five years, they insisted that their stay was temporary and that, therefore, they could not send their children to school.

Beyond the expressed intention to stay in Ghana for a short period lay other factors that kept the children of these migrants out of school. A Nigerian migrant parent, Randa, explained:

We are here primarily to seek economic advancement. We did not migrate with all our children as those left at home are older and live on their own. We arrived two years ago. That explains how come the children are not in school. We didn't come here to stay so our children will not go to school. That's not part of our plans of coming to Ghana. We came here because of poverty.

The interview with Mustapha Ibrahim echoed this point:

I am fourteen years. I come from Niger. I have been in Ghana for only four months. I do not go to school. I am out of school because my father said we are not going to stay here for the whole schooling period. He therefore cannot take me to school. He said we have our own system of schooling back home, i.e. our own style of writing and learning, so he will send me to school when we go back home. 
The research revealed that most people who cited their short stay as a reason for their plight had other underlying reasons. The likelihood of a migrant child staying out of school also depended on factors such as the values and beliefs of parents, the age of children at the time of immigration, the nature of migration, the economic position of the family, and the social support received. The reasons enumerated for migrants' nonattendance of school often did not act in isolation but were inextricably intertwined.

\section{Age at Immigration}

Several studies attest to the role that school-level factors (pupil-teacher relationship, classroom management, teacher instructional behavior, ability grouping, tracking, diversity, etc.) play in impeding the progress of immigrant students in school (Buckland, 2011; Crush \& Tawodzera, 2011; Heckmann, 2008; Nusche, 2009; UNICEF, 2005). Interviews with school authorities showed the correlation between age at immigration and completion of basic school in Ghana. These interviews exposed that migrants who moved into Ghana at older ages were more prone to dropping out of school than migrants who migrated to Ghana at younger ages, who adjusted better to challenges in school, most notably language. School authorities cited examples of migrants who entered school at older ages and struggled to adjust to the school system, subsequently dropping out. Challenges associated with integration for migrants who entered at older ages often had to do with their placement in lower-than-expected classes. Teachers and head teachers gave accounts of how the placement of older migrants in classes with relatively younger classmates came with its own challenges (i.e. bullying, teasing, loneliness). These factors eventually pushed migrants out of school. Olivia, a teacher at the Shie Primary and Junior High School, posited:

The biggest challenge we have with those who are not from Ghana is usually associated with the placement. Most of the people I have encountered come to Ghana when they are old. It is always difficult finding the right classes for them. The age gap between them and the class is sometimes more than four to five years. Teaching and managing them becomes very difficult and they eventually drop out of school even before we write the final exams. 
Although most of the literature on age at the time of immigration and entering school is based on research conducted in the Global North (Basu, 2016; Beck, Corak, \& Tienda, 2012; Corak, 2011; Goldner \& Epstein, 2014), these studies showing a correlation between older age at the time of immigration and school noncompletion are consistent with the findings of this study of conditions in Ghana, notwithstanding differences characterizing the South-South migration setting. There is evidence that with respect to intra-West African migration the age of children at the time of immigration has a similarly negative impact on school completion. The age of immigration does not act in isolation but rather combines with other factors, such as language barriers and grade-level placement, among others.

\section{Cultural/Religious Values}

There is extensive research on the linkage between immigrants, schools, religion, and culture. Most of this work focuses on how religion and the sociocultural values of immigrants might make them likely candidates for dropping out of school (Adelman \& Taylor, 2015; Greenfield, 2006; Heckmann, 2008; OECD, 2015). Data from this work further confirms these studies that demonstrate sociocultural values can serve as a barrier to education (Adelman \& Taylor, 2015; Greenfield, 2006; Heckmann, 2008; OECD, 2015). Findings from this study show religion and culture prevent West African immigrants in Ghana from enrolling in schools. Unlike previous research that assigns religion and culture as factors that may force one to quit school (Adelman \& Taylor, 2015; Greenfield, 2006; Heckmann, 2008; OECD, 2015), in Ghana religion and sociocultural values prevented immigrants from enrolling in schools in the first place. In some instances, parents and children placed little value on schooling as a vehicle for achieving their goals and for the future. Parents and children cited the incompatibility of schooling with their beliefs and values, and some migrants perceived schooling as an actual threat to their culture, value systems, and norms. These migrants had conflicting views on the advantages of education. The research revealed these migrants were mostly from Niger. These were migrants who had been out of school in their countries of origin even before arriving in Ghana. During the interviews these migrants frequently referred to formal education as a "western concept" that was at variance with their beliefs. Formal education was described as foreign. Per the narrations of the migrants, the value and 
norms that guided their behavior in the societies they were coming from placed little value on formal education. More premium was given to learning the Quran. Issah Balkas of Niger explained:

For us we usually do not take our children to school apart from taking them to Madrassa [Qur'anic or Arabic school] to be able to read the Quran and write in Arabic. When a child is born, two or three years he or she is given to an alpha [Mallam] to start teaching him or her how to read the Quran. When the child is about six or seven he or she is assigned some work to do. This could either be commercial or domestic. In the case of a boy, he is asked to start herding goats, sheep, cattle, and camels. And in the case of a female, she is assigned domestic chores until puberty when she gets a husband. That is the way we do things.

He further added:

We do not agree with western education. It clashes with our culture and traditional values. We think western education will undermine our cultural values. Many examples abound of people who have sent their children to school in towns and cities only to return to disrespect our culture. This makes us careful in sending our children to school. We prefer they go to Madrassa where we know they will be safe and learn what is important for us.

Agali, a Nigerien migrant, also confirmed:

Besides Arabic, we do not do any kind of education. This has been there since our great grandparents. It has been there from generation to generation that we do not go to school. Our primary concern when it comes to education is to be able to read the Quran. That is all. Even in Niger I was not going to school.

When asked whether his short duration of stay (four months) had something to do with his inability to go to school, he retorted strongly, "I told you before, for us we do not go to school."

This position taken by migrant parents brings to the fore the portrayal of formal education as the incontrovertible good by which knowledge can be transmitted. It also shows the limited sense in which the processes of learning are defined, excluding any event that happens outside the confines of the classroom. The arguments put forth by migrants for not going to school only reinforce existing debates between formal and informal 
education. For this, Strauss (1984) advises a shift in focus on the formal or informal education debate. Rather there should be emphasis on the cognitive process rather than the categorization of the learning processes.

\section{Gender Norms and Values}

Gender is a critical feature of migratory movements in West Africa, as there has been a marked increase in the number of women moving across the region (Adepoju, 2008). The vulnerability levels fluctuate based on the roles and status accorded women by society. Children involved in migration within the West African region are prone to vulnerabilities that vary along gender lines (Regional Mixed Migration Secretariat [RMMS], 2017). Substantial gains have been made over the past 20 years with respect to female education in Ghana and, by extension, sub-Saharan Africa. That notwithstanding, research suggests the gender gap in education is most pronounced in sub-Saharan Africa. These educational discrepancies against women have hinged on the beliefs and attitudes of societies in Africa (Dube, 2015). These gender norms place girls' domestic contribution to the home above their personal education. Some migrants interviewed claimed to be coming from settings that frowned on educating their female children. This was the practice in their societies of origin, and they replicated it in their new country of residence. Milhas Hassan, a migrant parent, stated:

Back home in Niger my daughter [pointing to her daughter] was not going to school. I fear that when I take her to school and she mixes with the opposite sex when she is of age, something bad could happen and bring shame to me and the entire family. You know women are not supposed to be mixed with boys so she can be safe. Because of that I prevent her from going to school. She has two other brothers who have completed basic education.

Sixteen-year-old Fatou also added:

I have not been in Ghana for long. It has been close to five months. I am here with my husband to look for better opportunities. I got married three years ago. I got betrothed to my husband when I was 10 years and when I turned 13 my father married me off. I was never in school in Niger. For us, it is only boys who sometimes go to school. We stay at home, do the house chores, and keep the home. 
This confirms the claim by Chavatzia, Engel, and Hastedt (2016) that immigrant girls comprise the most vulnerable group least likely to be enrolled in school. The prominence of gender norms and values in the research findings, and the dearth in research dedicated to the gendered aspects of migration and education within the Ghanaian context, is noteworthy, especially in the current global and local scheme of things where there is increased focus on getting all educated, including the most vulnerable. These findings have implications on the agenda for gender equity in education. This also derails the progress being made to achieve gender equality as mentioned in the SDGs and all the other major international frameworks.

\section{Economic Reasons}

Migrants also cited cost and lack of affordability as a reason for keeping their children out of school in Ghana. Migrants who cited economic reasons to explain their inability to enroll children in schools fell into two main groups. The first group were those who had at one point accessed schools in Ghana but could not sustain funding because of the costs involved and, thus, had to drop out. The second group were those who cited their struggles in making ends meet as the reason for not enrolling children into Ghanaian schools in the first place. The second category of migrant children was made up of those who were enrolled in school prior to migrating but stayed out of school after migrating due to economic reasons. As one migrant parent, Rahima, explained:

I am Nigerian. I have been in Ghana for over fifteen years. I have four children. Two are in school and the other two are not in school. Those who are not in school are 17 years and 14 years respectively. They were initially in school but dropped out because I could not finance the education of all of them. They were older and had been in school for a while so they had to give way so the younger ones would also have their turn. Life is difficult for us here as we struggle to even feed ourselves.

Teachers and head teachers confirmed how many migrants dropped out of school due to economic challenges. They spoke more about the unaccompanied migrant children as those who often dropped out of school. According to one teacher: 
I had one guy who was a Nigerian. He was working and schooling at the same time. Initially he was a good boy. He was repeated. He disagreed and stopped school. He is now in town. He was initially a good student, spoke good English but has a tonation. The work took away his attention. He didn't write all his exams.

\section{Unaccompanied Child Migrants}

Much of the existing research on migration regards children as passive movers who only move in reaction to their parents' decisions to migrate. This idea of the child as a passive mover has been critiqued by Hashim (2004) and Whitehead, Hashim, and Iversen (2007) as a western concept that does not apply in other settings, especially West Africa. Unaccompanied child migration is common in Africa (Thorsen \& Hashim, 2011). According to research done in the European Union member countries, unaccompanied children are one of the most vulnerable groups of children during migration (Eurochild, 2016). "Out-of-school immigrant youth are more likely to be living away from their parents than are in-school immigrant youth in every age group" (Hill \& Hayes, 2007, p. 37).

According to the interviews conducted in this study, the reasons for migrating ranged from migrating in search of family members who had migrated earlier to migrating in search of better job opportunities. The quest to survive on their own took precedence over any other desire, as the safety net provided by family in their countries of origin was no longer available. Engaging in economic activity no longer became a matter of choice but a matter of survival. Thus, schooling was perceived by migrants as interfering with their quest to work and earn a living to survive.

As Boateng, a head teacher, said:

These migrants come into the country alone in search of better economic opportunities or to find a kinsman who had travelled earlier. They also on many occasions migrate to work as house helps. Due to the lack of support from either parents or family, they therefore have to work to survive, making it difficult for them to go to school or stay in school.

Ibu, a migrant child from Nigeria, explained:

I have been in Ghana for a while. I joined some people from my town. I am alone in Ghana and work at a car garage. I am learning to be a mechanic. The little money I get from the job is what I live on. It will be difficult for 
me to stop the job and continue school since in my country I used to go to school. In Ghana, it is impossible for me to go to school. I have no one here as I explained to you earlier.

The data from the field also revealed that, although unaccompanied child migrants traveled independently of any third party, the nature of kinship and social network ties that exist in West Africa often means that migrant children traveling alone nevertheless have networks of support on which they can rely. These findings reinforce similar conclusions drawn from previous research done in the area (Adepoju, 2008; Alber, Häberlein, \& Martin, 2010; Thorsen \& Hashim, 2011). The research uncovered that the out-of-school migrants were those without the support of kinsmen and social network. The unaccompanied migrant without network and social support was therefore more prone to stay out of school than those unaccompanied migrants who found support from kinsmen in their countries of present stay.

\section{Begging Child Migrants}

Migration functions as an economic coping or survival strategy for many families. Moreover, children are critical participants in the execution of this strategy. This often leaves children exposed to the ills associated with the decision to migrate, including the necessity to engage in street begging. The research revealed that migrant children engaged in begging in Ghana tend to fall into two categories. One group was comprised of children who had never been to school-whether in their countries of origin, in Ghana, or in another host country. These were mostly children from Mali and Niger who were found on the major streets of Accra in the company of parents and other siblings. Through the interviews, these migrant families described their motivation for coming to Ghana as a search for a better life and improved economic prospects. Many of these migrants were escaping drought conditions in their countries of origin. They placed no value on formal education and were also not open to new ideas. The children were used as instruments in soliciting for alms, as most parents perceived that people were more inclined to give to children than to adults. "It is easier for people to pity children and give them something than older people," Abala, a 17-year-old migrant, explained. Nigerien migrant parent Sekou said: 
Since we have no work doing in Ghana we all beg. Our children also do beg. People are usually kind to the children. That's how come we sometimes sit back and allow them to beg. Proceeds from the begging is what we use to survive in Ghana. Life back home was very challenging. We therefore decided to come to Ghana to beg. We had been informed by our tribesmen who had migrated to Ghana earlier that it was better to be here. We used to rear cattle and raise other animals back home. We had severe drought that destroyed our farming. Our children never go to school.

Fati, a migrant child, explained:

My sister and I do beg for our parents. I do not know about western education. We have never been to such schools before. I prefer to live in Niger because that is my home country and have more friends there. We are here just for better living conditions.

Buckland (2011) asserted the importance of formal institutional nodes and social network nodes in influencing decisions taken by migrants. The lack of formal institutional support for migrants in Ghana meant they were more inclined to be influenced primarily by the social network nodes to which they belonged. These groups of migrants, who the researcher observed, stayed within very close-knit kin networks with other migrants from the same culture and, thus, were more likely to be impacted by the negative school-going habits of fellow kinsmen caught in the out-ofschool-going net.

The second group of children found to be engaged in street begging were migrants who accompanied elderly or visually impaired parents or guardians. Migrant children in this context served as guides. These migrant children were not only accountable for their lives but the lives of the elderly who also depended on them. The interviews revealed that many of these children previously attended school in their countries of origin but were forced to abandon school in order to accompany their guardians or parents. This group of migrants were mostly found around the major mosques in Accra. These mostly Muslim migrants preferred the mosques as they believed almsgiving was an important part of the Islamic faith. Nigerien migrant parent, Moussah Aboubakar, explained:

As you can see I am old and my son is the one you see [pointing to his son of about 8 years]. He helps me on daily basis. He runs errands for me. That 
was why I brought him to Ghana. He was going to school back home in Niger. He was doing both the Arabic and the French schools.

Yaro, a ten-year-old Nigerien migrant, also explained:

I was born in Niger. It has been over one year since we came to Ghana. I used to attend school in Niger but because my father is a beggar and blind, I am the only one who takes care of him. I have other siblings. They are at Sowtuom. They are there with my mother. They attend school. We all cannot be in school so I sacrifice to take my dad around. I am the eldest child. I cannot really say anything about school in Niger.

The father of Yaro (who is visually impaired) confirmed the reason behind Yaro's inability to attend school:

It's true that school is good. I agree with you, but someone also must sacrifice. And once he is the eldest he is the one who sacrifices. As for Arabic school he does attend, but when it comes to secular education he doesn't. Through the begging I do, I may buy a sewing machine so he can learn a trade so he can fend for himself. I came to Ghana for the tranquility.

This group of migrant children was usually affected by the lack of family or network that allowed other family members to run errands and take care of the elderly or the disabled. The lack of family support in their new country of residence meant that their very survival depended only on what they did to survive.

Tahiru, a child migrant, narrated:

Back home I used to go to school. We had many people home to take care of my grandfather. In Ghana, I am only here with him, and as you can see I am all he has. I cannot go to school and leave him behind. He cannot do anything on his own.

\section{Seasonal Migration as a Barrier to Enrollment into Schools}

The educational disadvantages confronting children who travel with parents engaged in seasonal migration are enormous. The literature on barriers to school access confronting these children is extensive (Deep, 2017; Hadley, 2010; Mosse et al., 2002; Smita, 2008). Deep (2017) further argued that the nature of the migration makes it difficult to account for 
such children, and they are therefore effortlessly left out of school. The temporary nature of seasonal migration easily leads to a break in attendance of school. Abala, a 17-year-old migrant from Niger, stated:

I have been in Ghana with my father for about five months. This is not the first time we have come to Ghana. We do come from time to time. Since I started travelling with my father, I have had to stop school in my home country. When we come we don't stay for long. We have a farm back home we work on. When the farming season is over, we always come to Ghana. We have been doing this for about four years. When we come to Ghana we move from one town to the other trying to find something to do. We sometimes beg, help people in the market, and anything that will give us some money to take back home.

Tau, a Nigerian child migrant, explained how the temporary nature of migrating with the father has led to a break in school-going habits:

We kept moving all the time with my family. It has been three years now since I went to school. The last time I went to school was in Nigeria. I was about two years short of completing the basic school. I have stayed out of school for three years and don't know where to start from after all these years. I think it is better I continue with the shop assistant job I am doing other than going back to school.

The nature and type of migration also affected the migrant child's schooling. Migrants who kept moving from one country to another for relatively short intervals were also kept out of school. Samba, a migrant parent from Mali, explained:

This is the third country I have been to in the past two years. I am originally from Mali. Before coming to Ghana, I lived in Togo and Burkina Faso. I came directly from Togo to Ghana. I didn't stay for more than six months in either Togo or Burkina Faso. I have been migrating with my family in search of better opportunities. My children are two (boy and girl). They were all in school in Mali till we decided to migrate in search of a better standard of living two years back. I have not been able to send them to school because we have barely settled in any country since we started migrating. I know the importance of education and will definitely send them back to school if we finally get to settle in Ghana.

Bayo, a migrant child from Togo, also explained: 
I am in Ghana with my parents. We came to Ghana two years ago from our hometown Togo. I don't live with them now. In Accra, I am on my own. My parents are at Aflao. Since we arrived in Ghana, we have been moving to several towns as we try to find what will work best for us. I had to leave the Volta region to Accra in search of a better job. In Togo, I used to help my parents in a shop. I used to attend a French school in Togo and was in class six. In Ghana, we keep moving from one place to the other. This is making it difficult for me to enroll in a school. I am keen on going to school, and once I get to find a permanent home in Accra, I will go to school.

\section{Decision-Making and Education}

Migration decisions taken by individuals are not done in isolation but in and between different groups of people. International migration is not only affected by extraneous elements but reinforced by relations between movers and stayers (Faist, 1997). The research on Ghana shows that the perceived economic benefits of migration were always prioritized at the expense of children's education. The effect of migration on the education of the migrant child was hardly, if ever, considered when deciding to migrate. The decision of whether to migrate or not was made on behalf of the migrant child by the parents and guardians. Most migrants interviewed explained that they had no choice other than migrating. With most migrants coming from places where society was organized on kinship ties, individual freedoms were curtailed through social groups in the form of conformity to societal norms. Child migrants in many cases had been socialized to accept the responsibilities they had to undertake during migration and offered little resistance, even when it affected their chances of attending school. Migrant children in many of the interviews agreed with their parents or guardians when it came to their decision not to send them to school.

\section{Conclusion}

The findings of this research show that factors that influence and determine whether migrant children are in or out of school are multifaceted. Migrant children who are outside the school system in Ghana do not constitute a monolithic group and, therefore, efforts aimed at assuaging their plight should be targeted, taking into consideration the disparate variables affecting their situation. The results of interviews conducted revealed that 
none of the migrant children in this study who were out of school had been denied access based on their legal status. The existing literature is awash with findings showing that migrants without the necessary documentation, especially in countries in the Global North, have difficulty accessing schools (Buckland, 2011; Crush \& Tawodzera, 2011; Nusche, 2009; PICUM, 2012). However, this research on Ghana reveals that, in the absence of a clear policy direction to guide migrant education, legal status and documentation appear to have a lesser, if any, impact on enrollment.

The existing literature on out-of-school migrants is heavily centered on those who drop out. However, the research undertaken in Ghana reveals that the prevalence of out-of-school migrants is more likely the result of decisions not to enroll in schools. The international migrant child's decision not to go to school in Ghana is less caused by school-level issues. This finding is a major contrast to work done by Makarova and Herzog (2013) on the hidden reasons why migrants stay out of school. Their work concluded that school-level factors have more prognostic ability in explaining why immigrants may choose to stay away from school than social background, a position this research sways from.

A survey of previous research on migrant education suggests that scholarship treats unaccompanied migrants as a monolithic group. This project speaks to the obvious negative implications of the strategy associated with previous scholarship by identifying several subgroups within the larger body of unaccompanied migrants. The unaccompanied child migrant without network support remains the most prone of the child migrants to be out of school. There are different constructions of what education means to parents and children engaged in intra-regional migration in Ghana. The meaning of education for parents and migrant children goes beyond the formal school to include Islamic education, household roles, as well as other forms of economic activity. As argued by Hashim and Thorsen (2011), education has thus become a socialization process regardless of whether it happens at home or outside the home.

Education is an investment that has opportunity costs beyond the direct costs involved. Thus, where the decision to invest in children's education comes with the cost of not being able to have children contribute economically (begging, working, etc.), migrant parents and children often decide otherwise. The decision not to enroll in school is made, as doing otherwise undermines the underlying reason for migrating in the first place. 


\section{REFERENCES}

Adelman, S., \& Taylor, L. (2015). Immigrant children and youth in the USA: Facilitating equity of opportunity at school. Education Sciences, 5(4), 323-344. Adepoju, A. (2008). Migration in sub-Saharan Africa. Uppsala, Sweden: Nordiska Afrikainstitutet.

Alber, E., Häberlein, T., \& Martin, J. (2010). Changing webs of kinship: Spotlights on West Africa. Africa Spectrum, 45(3), 43-67.

Awumbila, M. (2017). Drivers of migration and urbanization in Africa: Key trends and issues. New York, NY: United Nations.

Bartlett, L. (2015). Access and quality of education for international migrant children. Paris, France: United Nations Educational, Scientific, and Cultural Organization (UNESCO).

Basu, S. (2016). Age-of-arrival effects on the education of immigrant children: A sibling study. New York, NY: Western Economic Association International Conference.

Beck, A., Corak, M., \& Tienda, M. (2012). Age at immigration and the adult attainments of child migrants to the United States. Annals of The American Academy of Political and Social Science, 643(1), 134-159. Retrieved November 12, 2017, from https://ncbi.nlm.nih.gov/pmc/articles/pmc3478675

Braun, V., \& Clarke, V. (2006). Using thematic analysis in psychology. Qualitative Research in Psychology, 3(2), 77-101.

Buckland, S. (2011). Lost in transition: The barriers to educational access for schoolage Zimbabwe migrant children in South Africa and the influences of institutional and social networks on overcoming them (Doctoral thesis). Retrieved February 19, 2017, from http://sro.sussex.ac.uk/id/eprint/7522/1/ Buckland\%2C_Stephanie.pdf

Burra, N. (1995). Born to work. Child labour in India. New Delhi, India: Oxford University Press.

Chavatzia, T., Engel, L., \& Hastedt, D. (2016). Where are the immigrant girls? Amsterdam, Netherlands: The International Association for the Evaluation of Educational Achievement.

Christianakis, M. (2010). Lessons for life: Roma children, communal practices, and the global marketplace. Perspectives on Urban Education, 8(1), 11-18.

Corak, M. (2011). Age at immigration and the education outcomes of children. Ottawa, Canada: Institute for the Study of Labor (IZA).

Crush, J., \& Tawodzera, G. (2011). Right to the classroom: Educational barriers for Zimbabweans in South Africa. Cape Town, South Africa: Southern African Migration Programme (SAMP).

Deep, S. (2017). Seasonal migration and exclusion of children in school education. International Journal of Advanced Educational Research, 2(4), 1-7. 
Dube, T. (2015). Gender disparities in educational enrollment and attainment in sub-Saharan Africa. Journal of Educational and Social Research, 5(3), 279-284. Retrieved November 12, 2017, from https://papers.ssrn.com/sol3/delivery. cfm/ssrn_id2656544_code1795413.pdf?abstractid=2656544\&mirid=1

Eurochild. (2016). Turning the tide for children on the move. Brussels, Belgium: Author.

Faist, T. (1997). The crucial meso-level. In T. Hammar, G. Brochmann, K. Tamas, \& T. Faist (Eds.), International migration, immobility and development (pp. 187-217). Oxford, UK: Berg.

Ghana Statistical Service. (2013). The 2010 population and housing census: National analytical report. Accra, Ghana: Author.

Goldner, S. C., \& Epstein, G. S. (2014). Age at immigration and high school dropouts. IZA Journal of Migration, 3(1), 19. Retrieved November, 12, 2017, from https://link.springer.com/article/10.1186/s40176-014-0019-2

Green, P. (2003). The undocumented: Educating the children of migrant workers in America. Bilingual Research Journal, 27(1), 51-71.

Greenberg, E., Adams, G., \& Michie, M. (2016). Barriers to preschool participation for low-income children of immigrants in Silicon Valley: Part II. Washington, DC: Urban Institute.

Greenfield, P. M. (2006). Applying developmental psychology to bridge cultures in the classroom. In S. I. Donaldson, D. E. Berger, \& K. Pezdek (Eds.), Applied psychology: New frontiers and rewarding careers (pp. 135-152). Mahwah, NJ: Lawrence Erlbaum Associates.

Guba, E. G., \& Lincoln, Y. S. (1994). Competing paradigms in qualitative research. In N. K. Denzin \& S. Lincoln (Eds.), Handbook of qualitative research (pp. 105-117). Thousand Oaks, CA: Sage.

Hadley, S. (2010). Seasonality and access to education: The case of primary education in sub-Saharan Africa. Brighton, UK: University of Sussex, Consortium for Research into Educational Access Transition and Equity (CREATE).

Hashim, I. (2004). Working with working children: Child labour and the barriers to education in rural northeastern Ghana. Brighton, UK: University of Sussex.

Hashim, I., \& Thorsen, D. (2011). Child migration in Africa. New York, NY: Zed Books.

Heckmann, F. (2008). Education and the integration of migrants challenges for European education systems arising from immigration and strategies for the successful integration of migrant children in European schools and societies. Bamberg, Germany: European Forum for Migration Studies.

Hill, L., \& Hayes, J. (2007). Out-of-school immigrant youth. San Francisco, CA: Public Policy Institute of California.

Majgaard, K., \& Mingat, A. (2013). Education in sub-Saharan Africa. A comparative analysis. Washington, DC: International Bank for Reconstruction and Development/The World Bank. 
Makarova, E., \& Herzog, W. (2013). Hidden school dropout among immigrant students: A cross-sectional study. Intercultural Education, 24(6), 559-572. Retrieved November 12, 2017, from http://tandfonline.com/doi/full/10.10 80/14675986.2013.867603

Mosse, D., Gupta, S., Mehta, M., Shah, V., Rees, J., \& Team, K. P. (2002). Brokered livelihoods: Debt, labour migration and development in tribal western India. The Journal of Development Studies, 38(5), 59-88.

Nusche, D. (2009). What works in migrant education? A review of evidence and policy options. Paris, France: Organisation for Economic Co-operation and Development.

Organisation for Economic Co-operation and Development (OECD). (2015). Helping immigrant students to succeed at school and beyond. Paris, France: Author.

Organisation for Economic Co-operation and Development (OECD). (2016). Migration integrating refugees and other migrants into education and training. Paris, France: Author.

Platform for International Cooperation on Undocumented Migrants (PICUM). (2012). Undocumented children: Barriers to accessing social rights in Europe. Brussels, Belgium: Author.

Ratha, D., \& Shaw, W. (2007). South-South migration and remittances. Washington, DC: World Bank.

Regional Mixed Migration Secretariat (RMMS). (2017). Mixed migration in West Africa data: routes and vulnerabilities of people on the move. Copenhagen, Denmark: Danish Refugee Council, Regional Mixed Migration Secretariat.

Sabates-Wheeler, R. (2009). The impact of irregular status on human development outcomes for migrants. New York, NY: United Nations Development Programme.

Schapiro, K. (2009). Migration and educational outcomes of children. New York, NY: United Nations Development Programme.

Smita, S. (2008). Distress seasonal migration and its impact on children's education. Retrieved November 12, 2017, from http://sro.sussex.ac.uk/1869

Stevenson, A. D., \& Beck, S. A. (2017). Migrant students' emergent conscientization through critical, socioculturally responsive literacy pedagogy. Journal of Literacy Research, 49(2), 240-272. Retrieved June 30, 2018, from http:// journals.sagepub.com/doi/abs/10.1177/1086296x16683418

Strauss, C. (1984). Beyond 'formal' versus 'informal' education: Uses of psychological theory in anthropological research. Ethos, 12(3), 195-222.

Thorsen, D., \& Hashim, I. M. (2011). Child migration in Africa. Uppsala, Sweden: Zed Books.

United Nations Conference on Trade and Development (UNCTAD). (2017). Economic development in Africa report 2018. Migration for structural transformation. New York, NY: United Nations. 
United Nations Development Programme (UNDP). (2009). Human development report 2009. Overcoming barriers: Human mobility and development. New York, NY: Author.

United Nations Educational, Scientific and Cultural Organization (UNESCO). (2010). Education for all global monitoring report: Reaching the marginalized. Oxford, UK: Oxford University Press.

United Nations Educational, Scientific and Cultural Organization Institute for Statistics (UIS). (2017). More than one-half of children and adolescents are not learning worldwide. Montreal, Canada: Author.

United Nations Educational, Scientific and Cultural Organization Institute for Statistics (UIS) \& Global Education Monitoring Report (GEMR). (2016). Leaving no one behind: How far on the way to universal primary and secondary education? Montreal, Canada and Paris, France: Author.

United Nations International Children's Emergency Fund (UNICEF). (2005). The rights of all children in the context of international migration. New York, NY: Author.

United Nations International Children's Emergency Fund (UNICEF). (2017). Education uprooted: For every migrant, refugee and displaced child, education. New York, NY: Author.

Whitehead, A., Hashim, I. M., \& Iversen, V. (2007). Child migration, child agency and intergenerational relations in Africa and South Asia. Retrieved November 12, 2017, from https://www.researchgate.net/publication/237336827_Child_Migration_ Child_Agency_and_Intergenerational_Relations_in_Africa_and_South_Asia_1 
Open Access This chapter is licensed under the terms of the Creative Commons Attribution 4.0 International License (http://creativecommons.org/licenses/ by $/ 4.0 /$ ), which permits use, sharing, adaptation, distribution and reproduction in any medium or format, as long as you give appropriate credit to the original author(s) and the source, provide a link to the Creative Commons licence and indicate if changes were made.

The images or other third party material in this chapter are included in the chapter's Creative Commons licence, unless indicated otherwise in a credit line to the material. If material is not included in the chapter's Creative Commons licence and your intended use is not permitted by statutory regulation or exceeds the permitted use, you will need to obtain permission directly from the copyright holder.

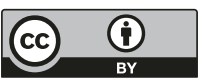

